\title{
Measuring Effectiveness of Persuasive Games Using an Informative Control Condition
}

\author{
Mara Soekarjo ${ }^{1 *}$, Herre van Oostendorp ${ }^{2}$ \\ 1*University College Utrecht, marasoekarjo@gmail.com \\ ${ }^{2}$ Utrecht University, h.vanOostendorp@uu.nl
}

\begin{abstract}
Research about the effectiveness of persuasive games is still emerging. This article presents a literature review of studies that empirically evaluate the effectiveness of persuasive games. The review concluded that limited empirical evidence is currently available to prove their effectiveness in attitude change. It further revealed that almost no study employed an informative control condition, making it difficult to conclude that the game was more effective than a control condition. Next, in a pretest-posttest design an empirical study tested whether change in attitude was different for people playing the persuasive game "EnerCities" compared to a control condition where participants read a document with highly similar information. No significant differences in increase of attitude or knowledge between participants that played the game and participants in the informative control condition were found. Based on the results of the literature review and the empirical study presented, it hence cannot be concluded that playing a game leads to a greater change in attitude or knowledge acquisition than experiencing conventional media would. Future work should employ designs with proper control conditions and focus on which game features lead to significant effects.
\end{abstract}

Keywords: Persuasive games, Serious games, Attitude change, Knowledge acquisition

\section{Introduction}

Encouraging sustainable energy use by individuals is one of the main challenges today. As we are rapidly running out of fossil fuels, ways to save energy have to be found. A considerable amount of energy is consumed by households. Consequently, household energy conservation can greatly impact energy conservation in general. In order to stimulate people to save energy, they need to be educated to induce an energy-friendly attitude. Scientists have argued that "when people change their attitudes, they change their behavior as well" [3]. Especially when it comes to the younger generation, it is of utter importance to increase awareness of energy conservation, as the need for energy conservation and alternative energy sources is likely to increase even more over the coming decades [46]. In this paper, we will examine how serious games can influence the attitude of consumers regarding energy conservation.

Researchers argue that serious games can be an effective means to change people's energy-related attitude. Serious games are games that are used for more than entertainment only; they build on the element of fun that games entail, but include an educational component as well [41]. So-called persuasive games are often classified as sub-category of serious games. The 'educational component' in these games is leveraged to persuade people to change their attitude or behavior [8] [18].

The mechanism through which this process occurs is that playing a game can lead to a state of flow or immersion, where players are extremely concentrated and time passes unnoticed as the game has completely taken over the player's attention [12] [38]. Generally, when people are highly engaged in the game they are apt to adopt the attitude that is promoted in the game [42]. These game characteristics can lead to a higher awareness of relevant factors involved in, for instance, energy saving. In effect, attitude may positively change and as such subsequently trigger a change in energy 
saving behavior itself. The assumed chain of events awareness-attitude change-behavior change is what persuasive games try to influence $[3,11]$. In this paper we will discuss evidence for this in our review. Next, in our empirical study we will - due to practical constraints we faced - focus on the first two events only, omitting behavioral changes.

A notable peculiarity within the field of game research is that although many scholars emphasize the substantial persuasive potential of games, little empirical research has been conducted that shows clear overall effectiveness of these games [24] [35]. Due to this lack of scientific evidence - see literature review below for a more extensive discussion of this observation -, it cannot be automatically concluded that games indeed have such attitudinal effects as game theorists often claim. Furthermore, a question that can be posed is whether it is actually the game and its features that aid the persuasive process or whether it is the persuasive content in the game that is responsible for the persuasion, regardless of the medium through which it is presented. In terms of Mayer's [35] game research designs, this would be a question fitting the genre of "media comparison" research, in which the main question is whether people learn better from a game or from conventional media such as narration or reading a slideshow. The research questions this paper will deal with are thus whether there is really an effect of persuasive games and whether the eventual change can be attributed to the game and its inherent features.

First, a literature review will evaluate the available literature on this matter. Next, an empirical study will be conducted that examines how effective the persuasive game EnerCities [14] is in changing players' energy-related attitudes while employing a research design with a proper informative control condition (see also [20]). This control condition will consist of information and design highly similar to that in the game, but instead presented in a non-game setting. Such a control condition allows for an actual media comparison to see whether it was the game or the information in the game that persuaded players and changed attitudes. The aim of this empirical study is hence to investigate and answer this paper's research question of whether there is really an effect of playing a persuasive game on attitudinal change, even when a proper control condition is used.

\section{Literature review of persuasive games}

Are persuasive games actually effective in accomplishing their persuasive goal? A literature search was conducted to identify empirical studies that attempt to validate actual effects of persuasive games. A media comparison approach will be used to investigate whether there is empirical evidence indicating that people are persuaded more by a persuasive game than by conventional media.

\subsection{Methodology}

Persuasive games were searched mid 2014 with search terms such as persuasive game, serious game, edutainment game, game attitude change, effectiveness game, educational game, persuasive game attitude and evaluation persuasive game. Games were also found in articles about persuasive games referring to other games and in proceedings of the European Conference on Games Based Learning.

Topics of games selected for the analysis included health, sustainability, interpersonal behavior, social or civic competences, cultural or political awareness, ethnic behavior, peer pressure, management attitudes or judgment.

\subsection{Overview games found}

Sixty games were found via the above-described methods. The oldest game was published in 1990, whereas three studies testing the effectiveness of a persuasive game were only published in early 2014. Regarding forty-five of the games found (75\%), either no scientific research about their effectiveness had been conducted, or there were only papers available in which preliminary plans for research were outlined. Of the remaining fifteen games, studies were found that empirically investigate their effectiveness. The following aspects were recorded for each of the games/studies: brief description of the game (i.e., year, topic), research design (i.e., control condition and moments of measurement), outcome measures (i.e., were change in attitude, knowledge and/or behavior measured?) and effects found (i.e. effects on attitude, knowledge or behavior) (see the Appendix). Important to note here is that both in selecting as well as in describing games for the review, the 
focus was on methodology and outcome measures. Examining other features/mechanisms of the game were left behind as examining those exceeds the scope of this paper.

\subsection{Effects found in persuasive games}

Table 1. Summary of results found in literature review

\begin{tabular}{|c|c|c|}
\hline Outcome measure & No. of papers & Summary of results \\
\hline $\begin{array}{l}\text { Change in } \\
\text { attitude }\end{array}$ & $6 / 15$ & $\begin{array}{l}\text { - Significant increase in attitude found after playing } \\
\text { game in most studies } \\
\text { Only } 1 \text { game did not find significant attitude } \\
\text { increase } \\
\text { - No clear trend on sustaining change attitude in } \\
\text { long-term }\end{array}$ \\
\hline $\begin{array}{l}\text { Change in } \\
\text { knowledge }\end{array}$ & $9 / 15$ & $\begin{array}{l}\text { - Significant increase in knowledge after playing } \\
\text { game found in } 5 \text { studies. } \\
\text { Increased awareness found in two studies after } \\
\text { playing game. } \\
\text { - In } 2 \text { studies qualitative account of increased } \\
\text { knowledge found. } \\
\text { - } 2 \text { studies did not find significant increase in } \\
\text { knowledge after playing game. } \\
\text { No effect of increased knowledge on long-term } \\
\text { could be found. }\end{array}$ \\
\hline $\begin{array}{l}\text { Change in } \\
\text { behavior }\end{array}$ & $4 / 15$ & - $\quad$ Positive effects found in 3 papers. \\
\hline
\end{tabular}

Table 1 provides a summary of the results of the literature review: it shows which outcome measures were studied in how many of the papers found, followed by a summary of what those papers found. More specifically, the literature review revealed that very few studies about persuasive games are actually devoted to empirically investigating attitudes in their research: only six of the fifteen papers found directly evaluated change in attitude. Most of these studies reported a significant increase in attitude when comparing attitudes before and after the game (i.e. the attitude becomes more favorable towards the topic of the game), e.g. in the games Birthday Party [19], PeaceMaker [10] [1] [21] and PowerExplorer [22]. Only one of the games used in this literature review did not find that participants had a significantly increased attitude after playing the game [31]. No clear trend in whether increased attitude is sustained on the long-term can be found. Gerling et al. [19] found that some attitude measures remained at a higher level than baseline level after playing Birthday Party [19]. Lavender [32] on the other hand did not find significant long-term effects of playing Homelessness: it's no game.

In nine out of fifteen studies found, researchers report on the change of knowledge measurable after playing a persuasive game. In Clot Buster [48], Mystery of Taiga River [5] [6], Re-Mission [26], RightWay Café [39] and Stop Disasters! [15], the researchers of the respective articles show that knowledge of participants that have played the game increases significantly. Research about the games Stop Disasters! [15] and EnerCities [14] [30] also found increased awareness after playing the game, which can be considered an indirect account of increased knowledge [13]. In the games Shortfall [25] and Shrub Battle [37], increase in knowledge is also mentioned by the authors, but these changes are either self-reported by participants rather than objectively tested, or the research is qualitative and not supported by statistics. On the contrary, studies investigating the knowledge participants gained after playing Homeless: it's no game [31] [32] and Power Explorer [22] did not find a significant increase of knowledge after playing the game. Four of the studies that investigated change in knowledge after playing a game used follow-up measurement in addition to pretest and posttest measurement (i.e., [25] [32] [39] [48] ). None of these four studies found that the effect of increased knowledge was sustained on the long term.

Changes in behavior were studied in only four of the fifteen papers. Three of these four studies found positive effects. Kato et al. [26] and Baranowski et al. [7] found that participants significantly 
increased treatment adherence after playing Re-Mission and significantly increased their consumption of fruit, juices and vegetables after playing Squire's Quest respectively. Gustafsson et al. [22] showed that participants consumed less energy both while playing Power Explorer as well as after gameplay. In the follow-up game Power Agent, however, Gustafsson et al. [23] found that whereas energy consumption decreased during the game, it increased right after and before the game was played.

\subsection{Research designs used in studies about persuasive games}

Two aspects of research designs were looked at: moments of measurement and (the construction of) the control condition (see also table 1). When looking at the former, it becomes apparent that almost all of the studies use at least a pre-test and post-test measurement. The study about EnerCities is the only one that does not use pre-test measurement and employs a posttest-only design. Because Knol and De Vries [30] only use post-test scores to investigate differences between the experimental and the control condition, they do not take the baseline attitude into account in their study. This makes it impossible to get a precise account of the change in attitude per individual. Six of the studies use a follow-up measurement, yet almost none of them extensively mention evidence of long-lasting effects of attitude change.

Eight out of fifteen studies employ a control condition. Interestingly enough, in all but one of those eight the control condition simply exists of a 'no info' control condition, in which participants only fill in questionnaires twice (e.g., in Power Explorer, Mystery of Taiga River and in Squire's Quest). Only one study found, i.e. the study conducted by Lavender [31] [32], used a 'narrative' control condition in addition to a 'no info' control condition and an experimental (game) condition. This design is by far the most interesting design to test a media comparison question of whether people are persuaded to a larger extent by games than by conventional media, because it allows for the possibility of directly testing whether it was playing the game (in the experimental condition) or merely presenting the information (in the 'narrative' control condition) that persuaded the player. Lavender [31] [32] however did not find a significant change in either interest in or attitude towards homeless people from pre-test to post-test measurement in either three of his conditions. Be that as it may, participants that played his game Homelessness: it's no game did become significantly more sympathetic towards homeless people as opposed to people who read a narrative similar to the content of the game or did not engage in any special activity related to homelessness.

The main conclusion that can be drawn from this literature review is that empirical research specifically about the effectiveness of persuasive games on change of attitude of players is still scarce. Only six out of the sixty games found were empirically tested on their attitude changing potential. Most of the existing studies about these games found a positive effect of playing the game on attitudes of players towards the topic, but one of the studies did not: the study conducted by Lavender [31] [32]. Remarkably, this study was also the only one of the studies found that employed a research design that included both multiple measurement moments (to allow for measuring a precise change in attitude per individual) as well as a proper control condition with similar information as presented in the game (to allow for media comparison research, cf. [35]). The other studies that used a control condition stuck to using a control condition in which no information to participants in this condition was presented.

Five studies reported statistically significant increases in knowledge after playing a game. Two studies provided indications of increased knowledge via self-reports or qualitative research and two studies showed increased awareness. Overall, most of the literature seems to suggest that knowledge indeed increases after playing a persuasive game. But as mentioned before, all these studies used either no informative control condition or only a 'no info' control condition, which disregards the media comparison question. The only study that employed a research design in which a control condition allowing for such a media comparison was included (i.e., Lavender's study) did not find significant changes in knowledge. The next study will examine this issue further by using a control condition that received information highly similar to the game condition. 


\section{Study into EnerCities}

\subsection{Cognitive Training Task}

The current study used the game EnerCities in an experimental condition. EnerCities is a persuasive game about sustainable energy use in which players have to balance environmental and economic needs as they build their own city (Figure 1 and 2 show a screenshot of the game). The aim of the game is to "increase awareness and attitudes relating to energy use in the household" [30]. The game was selected for this research because previous research had reported the game to be successful in changing people's attitudes ([30]. In large-scale research $(n=653)$, students from five different European countries played the game EnerCities and filled out questionnaires related to their attitude toward energy use. Results showed that the game was effective in increasing awareness and increasing positive attitudes related to energy use. The researchers hence conclude that playing the game EnerCities has positive effects, as their experiment showed "higher environmental and energyrelated awareness ratings for students who had played EnerCities compared to those who had not [and that] attitudes towards energy-related behaviors in the household were generally more positive for students who had played EnerCities compared to the control group members" [30] p.9 ). Other reasons to use the game EnerCities for the present study are that it was available for free, rating measures could be adopted from previous research (e.g. [9] [28] [30]) and that the game had won both national and international awards [30]. Just because of these results we may assume that EnerCities is a well-designed persuasive game that possesses stimulating game features. The game is available at www.enercities.eu and was developed for the European Commission.

The present study partially replicates the study conducted by Knol and De Vries [30], because:

1. it uses the game EnerCities as persuasive game in the experimental condition; and

2. it adopts the five micro-level attitude questions that Knol and De Vries used to measure attitudes; and

3. it uses an experimental condition and a control condition in which participants do not play the game to investigate between-participant differences.

The present study differs from the original study in that it includes an informative control condition with highly similar information and design in a non-game setting whereas the original research did not. Second, this study uses university students as participants whereas Knol and De Vries used secondary school students. Lastly, the original study used statements about energy use that deal with the topic on a 'micro-level' to assess participants' attitudes. These statements for instance deal with taking shorter showers or turning off the TV instead of using the standby mode. The authors mention that there is a difference in scope of the game and their questionnaire: "The EnerCities game required its players to take a global stance and build and expand a city [...]. The questionnaire on the other hand focuses on a more microscopic level of behavior, namely the energyrelated behaviors in the household."'[30] p.4. Since the authors mention this in the limitations of their paper, macro-level attitude measures were constructed for the present study to see whether a similar effect could be found when focusing on macroscopic behaviors.

The present study will use a pretest-posttest design. Both participants' knowledge as well as their attitude regarding sustainability-related topics will be assessed. Their attitude will be tested regarding micro-level as well as macro-level topics. Participants are randomly divided amongst two conditions: the experimental condition (playing EnerCities) and the control condition (reading similar information). This empirical study will answer the research question of whether there is really an effect of playing a persuasive game on attitudinal change, even when a proper control condition is used. Based on the literature review conducted, we hypothesize that the (micro and macro-level) attitude and knowledge of participants playing the game will increase more than that of participants in the informative control condition. 


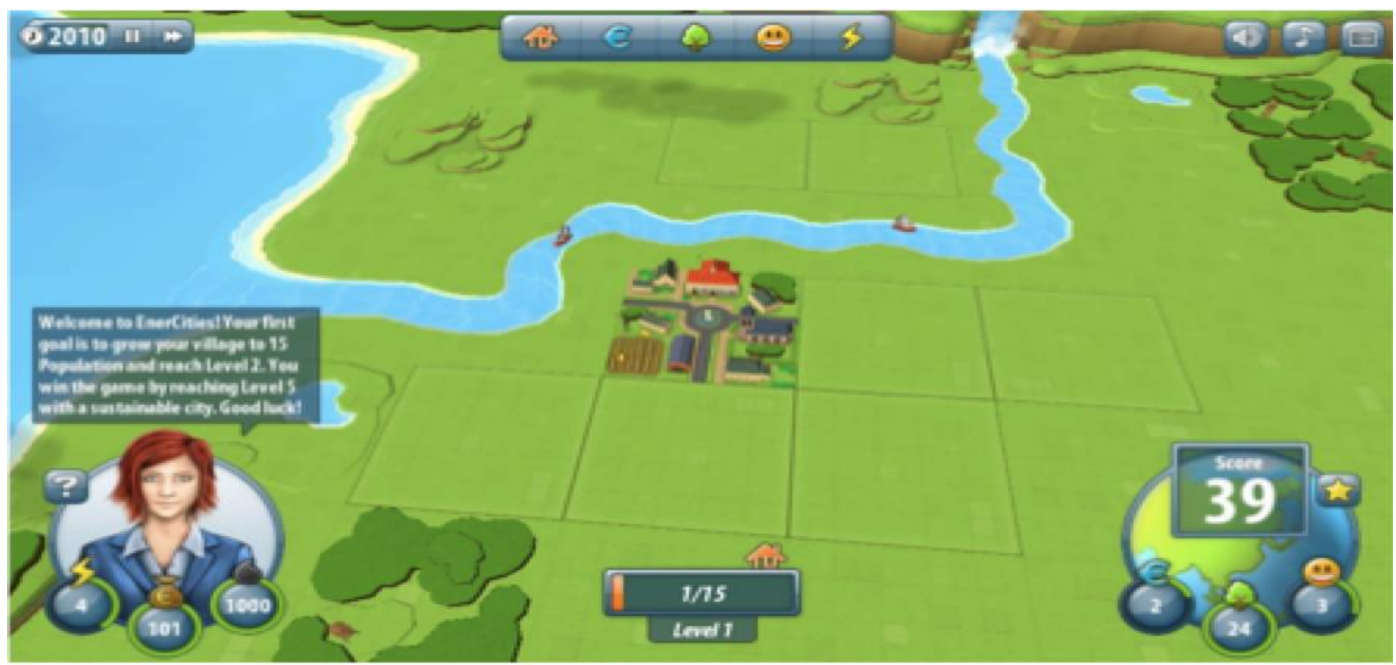

Figure 1. Start Screen of the Game EnerCities

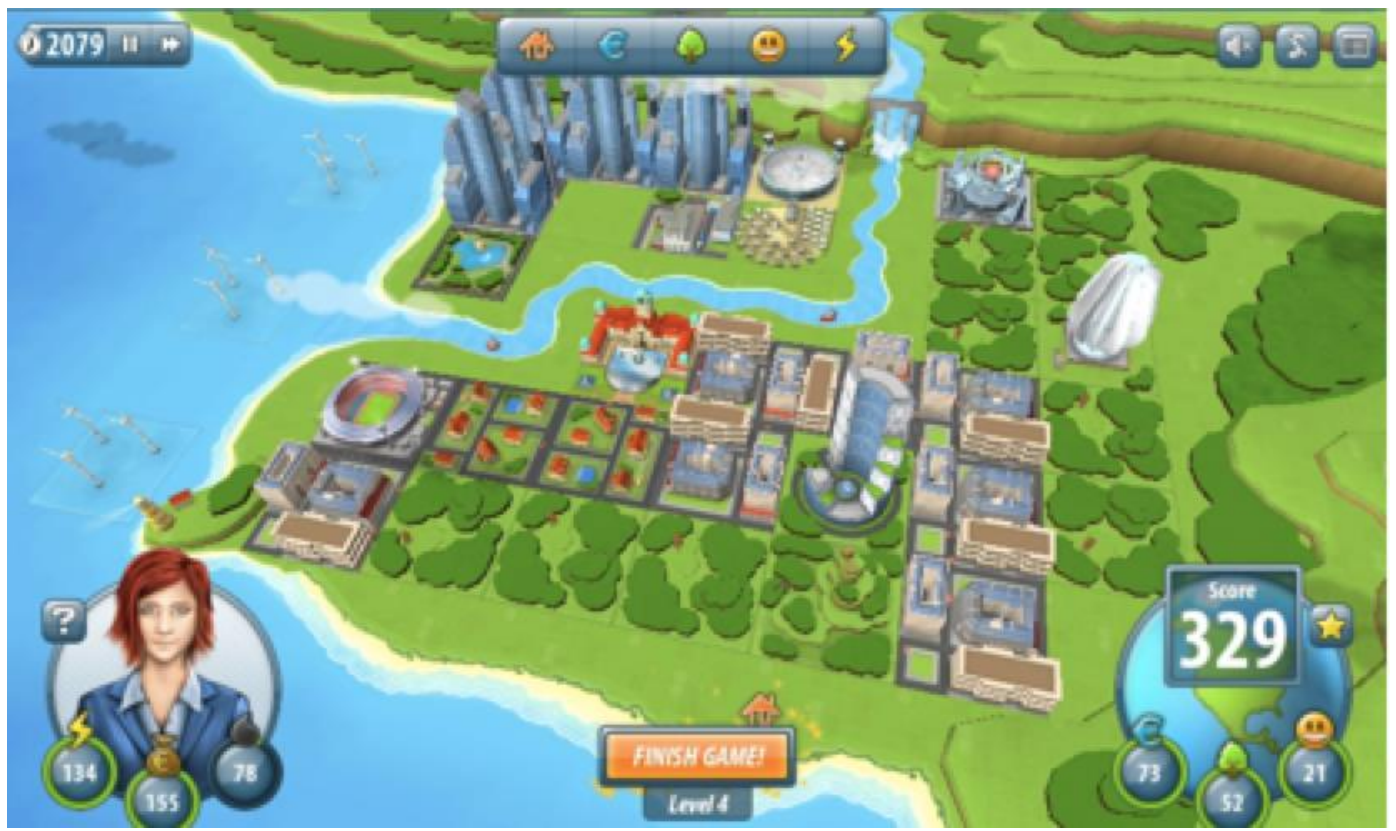

Figure 2. Screenshot of the Game EnerCities near the End of the Game

\section{Method}

\subsection{Participants}

In this study 46 (18 male and 28 female) undergraduate students between the ages of eighteen and twenty-five $(\mathrm{M}=20.52, \mathrm{SD}=1.36)$, participated on a voluntary basis. They were divided randomly over the two conditions such that both conditions had 23 participants. The majority of students, 36 out of 46, had a Dutch nationality. The other participants had a nationality from a different European country (e.g., German, Spanish, British).

\subsection{Control condition}

As an informative control condition, a Powerpoint presentation was constructed that included information highly similar to the information and design presented to participants in the game (similar to [44]). It should be acknowledged that it is very difficult to make the information in the 
Powerpoint $100 \%$ similar to the game, but extensive efforts were made to ensure that as much as possible was similar in the game and the Powerpoint. In order to recreate the design ('look and feel') of the game in the presentation, screenshots of the game were used to supplement verbal explanations (see Figure 3). Moreover, the text in the presentation was written in such a way that it would be highly similar to the style of the text in the game. The Powerpoint was introduced as "an introduction to sustainable city development" and included a description of buildings to be found in cities and explained the same five categories presented in the game. Per building, energy efficiency improvements that were also presented in the game were explained, and advantages and disadvantages of each building were discussed in a way highly similar to the game. In order to illustrate the importance of balancing energy needs, three situations in the game were used as examples in which a trade-off had to be made between economy and environment. The presentation consisted of 37 slides.

\subsection{Measurement instruments}

Participants completed an online pretest as well as an online posttest questionnaire, both of which included several rating scales to assess participants' attitude toward sustainability-related topics. The pretest questionnaire served as baseline measurement in order to later calculate the change in attitude (difference score) of each participant (see also [4] [39]).

Both questionnaires included statements regarding micro-level topics (e.g., attitude toward lowering the heating at home or toward taking shorter showers) as well as regarding macro-level topics (e.g., attitude toward governments subsidizing solar panels or toward taxing $\mathrm{CO} 2$ emissions). Micro-level attitudes were investigated based on three subscales allowing for a comparison the results of this study with the original study by Knol and De Vries [30]. In the first subscale, participants were asked to rate five statements on a 7-point Likert scale ranging from respectively extremely bad to extremely good (Cronbach's $\alpha=.80$ at pretest; Cronbach's $\alpha=.85$ at posttest). The second subscale entailed the same questions, but this time participants were asked to rate the statements on a 7-point Likert scale ranging from extremely unpleasant to extremely pleasant (Cronbach's $\alpha=.80$ at pretest; Cronbach's $\alpha=.76$ at posttest). In the third scale, the rating ranged from not at all useful to extremely useful (Cronbach's $\alpha=.82$ at pretest; Cronbach's $\alpha=.89$ at posttest). For each of the five statements, the mean score on the three different subscales was computed (Cronbach's $\alpha=.79$ at pretest; Cronbach's $\alpha=.87$ at posttest). Averaging over the five statements resulted in a composite micro-level attitude index. The above presented Cronbach's alpha coefficients indicated that all of these scales, both at pretest and at posttest, had relatively high reliabilities [16].

Since Knol and De Vries [30] mentioned the lack of assessment of macro-level attitudes as a limitation of their study, macro-measures were composed based on previous research on attitudes toward sustainability [36] and based on topics present in the game. All macro-measures were rated on a 7-point Likert scale ranging from strongly disagree to strongly agree. Three out of eight statements were phrased in such a way that a low instead of a high score indicated a favorable sustainable attitude. The rating of these statements was hence reverse scored (Cronbach's $\alpha=.75$ at pretest; Cronbach's $\alpha=.73$ at posttest). Results of the eight items were summed and averaged to compute a scale measuring the composite macro-level attitude index. 


\section{Housing}

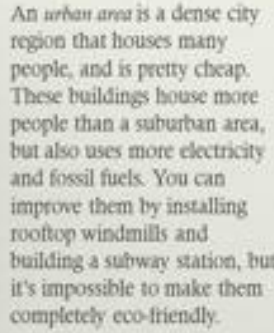

\section{Energy coal plants}

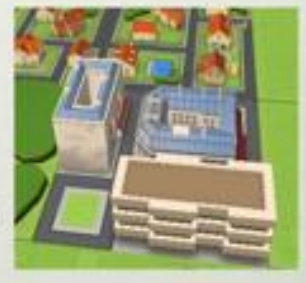

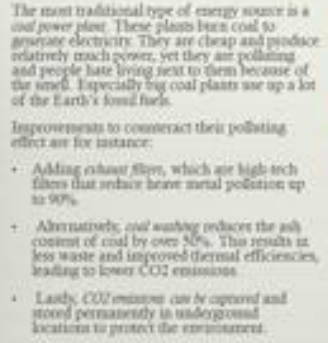

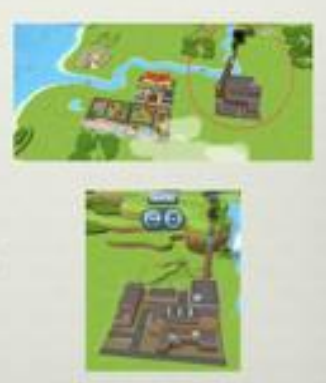

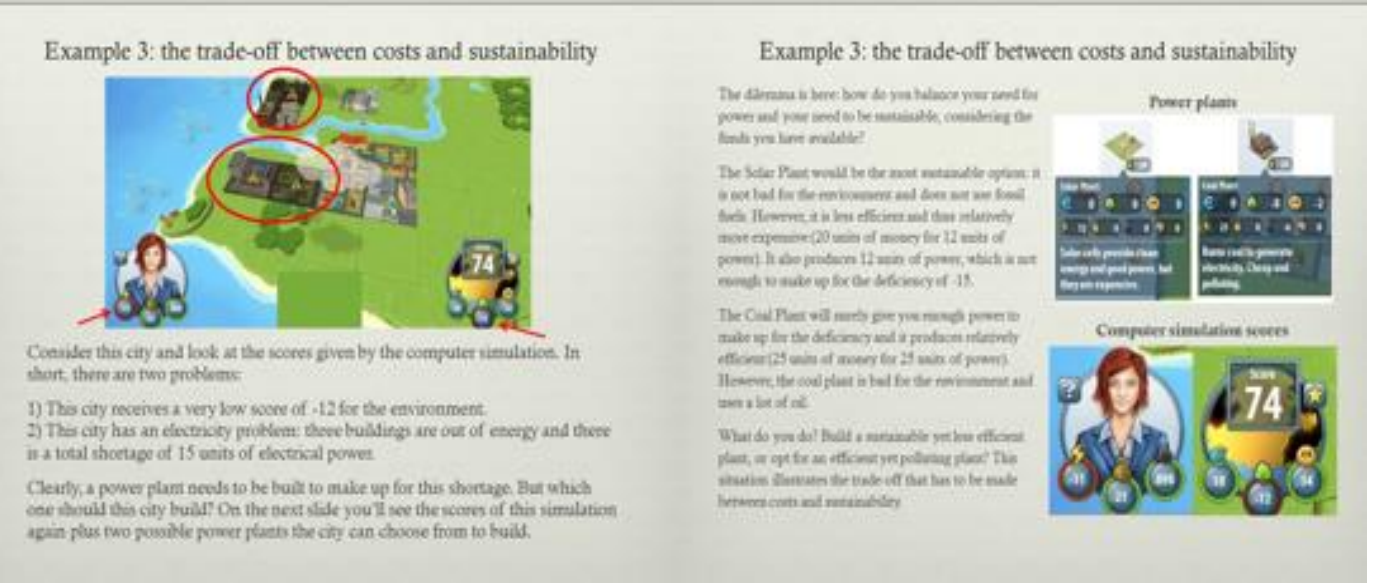

Figure 3. Some Slides from the Informative Control Condition

In addition to attitude measures, the pretest and posttest questionnaires also included a knowledge measure in the form of open questions. These measures were used to assess the extent to which knowledge about sustainability topics increased after playing the game or reading the Powerpoint presentation. The questions were partially based on previous research using EnerCities as game in the experimental condition [9] [28] and were adjusted for the current study so that participants in both conditions should theoretically be able to answer the questions. In total, participants could earn a maximum of fifteen points for the knowledge questions, max. three points for each of the five questions. Results of these five items were summed to compute a composite knowledge scale. At pretest, the knowledge scale had a Cronbach's $\alpha=.73$, which indicates a relatively high reliability. However, the scale had relatively low reliability at posttest, Cronbach's $\alpha=.59$, but given the small number of items (5) this is still acceptable.

Lastly, the posttest questionnaire also included five rating scales to evaluate the information presented to participants in the game or Powerpoint presentation. Participants rated how interesting they found the game or Powerpoint presentation, how much they enjoyed it, how credible they found the information presented, how much the information was personally relevant to them and how much they learned from it.

\subsection{The distractor task}

In order to clear participants' short-term memory before filling out the questionnaire after reading the Powerpoint presentation or playing the game, participants were shown a four-minute YouTube video with a funny scene about a man greatly interested in the environment.

\subsection{Procedure}

The online pretest questionnaire was sent to 49 participants and was completed at home. The pretest questionnaire was conducted a week before the posttest in order to reduce the chance of sensitization, in which results at a subsequent measurement are potentially amplified due to repeated 
measurement [43]. Out of these 49, 46 participants completed the questionnaire. This study employed a pre-test post-test design with two conditions. A week later, these 46 participants were randomly assigned to either the game condition, in which participants played EnerCities for twenty minutes, or to the informative control condition, in which participants read the Powerpoint presentation. Pretesting had revealed that reading the presentation took on average 20 minutes, which was hence decided on as the time that participants were allowed to play the game for. Participants in the control condition were allowed to navigate freely in the Powerpoint presentation. Participants in the game condition first read a short Powerpoint presentation explaining the aim of EnerCities and read instructions for gameplay. Participants were then allowed to play the game for twenty minutes. In addition the informative control condition also started with a slide with instructions on what to pay attention to, in order to maintain similarity to the game condition. After participants either finished playing the game or reading the Powerpoint, the experimenter started up the YouTube video that took about four minutes to watch. Lastly, participants filled in the online posttest questionnaire.

\section{Results}

\subsection{Micro-level attitudes}

A multivariate test of variance was conducted to see whether the change in attitude was different between the two conditions. Difference scores were calculated by subtracting the attitude score at pretest measurement from score at posttest measurement. Thus, positive difference scores indicate an increase in energy-related attitudes (See table 2). The MANOVA on the difference scores on the five micro-level attitude measures turned out to be not significant between the two conditions, $\mathrm{F}$ $(5,40)=.30, p=.91$. It can therefore be concluded that there are no statistically significant differences between the two groups regarding their change in micro-level attitudes about energy use after either playing the game or reading the Powerpoint presentation.

As can be seen from table 2, micro-level attitudes even increased more for all five of the measures in the control condition than in the experimental condition. The composite micro-level attitude index also indicates a larger increase in the control condition. However, these differences are not statistically significant, yet they do suggest a trend of larger increases of attitudes in the control condition. The table also shows that almost all difference scores (except for the attitude towards switching off lights in unoccupied rooms for the experimental condition) are positive. This indicates that in almost all cases, both playing the game and reading the Powerpoint (somewhat) increased people's attitudes on a micro-level toward sustainable energy use, but this effect was not statistically significant. Focusing on the composite index, we analyzed the increase in micro-level attitude over time. Paired t-test showed that the difference between pretest and posttest measurement was not significant for the game condition $(\mathrm{t}(22)=.76, \mathrm{p}=.46)$ nor for the control condition $(\mathrm{t}(22)=1.88$, $\mathrm{p}=.07$ ), indicating that micro-attitude in both conditions did not significantly increase over time.

Table 2. Means, standard deviations and significance levels of difference (post-test - pretest) ratings of micro-level attitudes in both conditions

\begin{tabular}{l|l|l|l|l|l|l}
\hline & \multicolumn{2}{|l|}{ Exp. cond. } & \multicolumn{2}{l|}{ Control cond. } & \multicolumn{2}{l}{ Significance } \\
& $\mathbf{M}$ & $\mathbf{S D}$ & $\mathbf{M}$ & $\mathbf{S D}$ & $\boldsymbol{F}(\mathbf{1 , 4 4 )}$ & $\boldsymbol{p}$ \\
\hline $\begin{array}{l}\text { Attitude towards switching off lights in } \\
\quad \text { unoccupied rooms }\end{array}$ & -.03 & .59 & .09 & .75 & .34 & .56 \\
\hline Attitude towards lowering the heating & .16 & .80 & .19 & .61 & .02 & .89 \\
\hline Attitude towards saving energy at home & .07 & .45 & .22 & .79 & .59 & .45 \\
\hline Attitude towards taking shorter showers & .09 & .60 & .22 & .62 & .53 & .47 \\
\hline $\begin{array}{c}\text { Attitude towards turning off TV instead of } \\
\quad \text { using standby }\end{array}$ & .07 & .75 & .16 & .65 & .18 & .68 \\
\hline Composite Micro-level attitude index & .07 & .46 & .17 & .44 & .58 & .45 \\
\hline
\end{tabular}

\subsection{Macro-level attitudes}

When considering the difference scores (posttest attitude score - pretest attitude score) for the eight macro-level attitude measures, no statistical differences were found between the two groups: $\mathrm{F}$ $(8,37)=.49, \mathrm{p}=.86$. In other words, the multivariate analysis of variance showed that there were no 
significant differences between the change in macro-level attitudes of participants that read the Powerpoint and of participants that played the game.

As can be seen in table 3, macro-level attitudes increased more for participants who played the game than for participants who read the Powerpoint presentation for four out of eight measures. For two measures, attitudes of participants in the control condition increased more. For one measure, attitudes decreased in both conditions yet did so less in the control condition. Lastly, for one measure attitudes in the control condition decreased whereas they remained the same in the experimental condition. However, it should be noted that none of these differences were significant ( $p>.05)$. Based on the values of the macro-attitude measures, no clear trend can be found in whether playing the game or reading the Powerpoint presentation has resulted in a bigger change in attitude. The composite macro-level attitude index indicates a slightly larger increase in the experimental condition as opposed to the control condition, yet this difference is not significant ( $p>.05$ ) either. Focusing on the composite index, we analyzed also here the increase in macro-level attitude over time. Paired t-tests showed that the difference between pretest and posttest measurement was not significant for the game condition $(\mathrm{t}(22)=1.70, \mathrm{p}=.10)$ nor for the control condition $(\mathrm{t}(22)=.42$, $\mathrm{p}=.68$ ), indicating that macro-attitude in both conditions did not significantly increase over time.

Table 3. Means, standard deviations and significance levels of difference (post-test pre-test) ratings of macro-level attitudes in both conditions

\begin{tabular}{|c|c|c|c|c|c|c|}
\hline & \multicolumn{2}{|c|}{ Exp. cond. } & \multicolumn{2}{|c|}{ Control cond. } & \multicolumn{2}{|c|}{ Significance } \\
\hline & $\mathbf{M}$ & SD & $\mathbf{M}$ & SD & $F(1,44)$ & $p$ \\
\hline $\begin{array}{l}\text { Attitude towards educating children about } \\
\text { living sustainably. }\end{array}$ & .43 & .95 & .30 & .70 & 0.28 & .60 \\
\hline $\begin{array}{c}\text { Attitude towards governments and companies } \\
\text { investing in sustainable technologies. }\end{array}$ & .61 & 1.08 & .26 & .69 & 1.71 & .20 \\
\hline $\begin{array}{l}\text { Attitude towards governments subsidizing } \\
\text { solar panels on citizens' houses. }\end{array}$ & .00 & 1.04 & -.39 & 1.90 & 0.75 & .39 \\
\hline $\begin{array}{l}\text { Attitude towards building windmills and } \\
\text { solar plants as opposed to coal and } \\
\text { nuclear plants. }\end{array}$ & .17 & 1.07 & -.17 & 1.40 & 0.89 & .35 \\
\hline $\begin{array}{l}\text { Attitude towards insulation of houses to save } \\
\text { energy. }\end{array}$ & .21 & 1.09 & .00 & .85 & 0.57 & .45 \\
\hline $\begin{array}{l}\text { Attitude towards re-cycling and re-using } \\
\text { waste. }\end{array}$ & .17 & 1.03 & .30 & 1.36 & 0.13 & .72 \\
\hline $\begin{array}{l}\text { Attitude towards taxing } \mathrm{CO} 2 \text { emissions to } \\
\text { make polluters pay for the damage } \\
\text { they do. }\end{array}$ & .22 & 1.13 & .26 & 1.05 & 0.02 & .89 \\
\hline $\begin{array}{l}\text { Attitude towards the importance of the } \\
\text { environment compared to the } \\
\text { economy. }\end{array}$ & -.39 & .94 & -.26 & 1.29 & 0.15 & .70 \\
\hline Composite Macro-level attitude index & .18 & .51 & .04 & .44 & 1.03 & .32 \\
\hline
\end{tabular}

\subsection{Knowledge measures}

To examine whether the change in knowledge acquisition differed significantly between the two conditions, a MANOVA of the difference scores was conducted. No significant difference was found between the difference scores of the two conditions: $F(5,40)=1.30, p=.29$. It can thus be concluded that conditions did not differ significantly in the increase of their knowledge. Table 4 shows that in four out of five measures the knowledge of participants in the control condition increased more, whereas for only one measure knowledge of participants in the experimental condition increased more. The composite knowledge index also indicates a larger increase of knowledge in the control condition. It must be noted though that none of these differences were significant, except for the increase in knowledge regarding the efficiency of windmills. Still, the multivariate analysis showed no significant differences ( $p>.05$ ) between the two conditions so the on average larger increase of knowledge in the control condition can only be considered a trend. When looking at the increase in knowledge over time both playing the game and reading the Powerpoint significantly increased participants' overall knowledge of sustainable energy use: composite knowledge index game condition $\mathrm{t}(22)=4.69, \mathrm{p}<.01$, control condition $\mathrm{t}(22)=7.28, \mathrm{p}<.01$. 
Table 4. Means, standard deviations and significance levels of difference (posttest pretest) ratings of the knowledge measures in both conditions

\begin{tabular}{c|l|l|l|l|l|l}
\hline & \multicolumn{2}{l|}{ Exp. cond. } & \multicolumn{2}{l|}{ Control cond. } & \multicolumn{2}{l}{ Significance } \\
\cline { 2 - 6 } & $\mathbf{M}$ & $\mathbf{S D}$ & $\mathbf{M}$ & $\mathbf{S D}$ & $\boldsymbol{F}(\mathbf{1 , 4 4 )}$ & $\boldsymbol{p}$ \\
\hline $\begin{array}{c}\text { Knowledge of advantages and disadvantages } \\
\text { of solar plants. }\end{array}$ & .39 & .90 & .35 & .70 & .03 & .86 \\
\hline $\begin{array}{c}\text { Knowledge of making windmills produce } \\
\text { energy more efficiently. }\end{array}$ & .46 & .89 & 1.07 & .70 & 6.67 & $.01 *$ \\
\hline $\begin{array}{c}\text { Knowledge of slowing down the rate at } \\
\text { which natural resources are used. }\end{array}$ & .50 & 1.17 & .67 & 1.24 & .24 & .63 \\
\hline $\begin{array}{c}\text { Knowledge of advantages and disadvantages } \\
\text { of coal plants. }\end{array}$ & .37 & .91 & .48 & .75 & .20 & .66 \\
\hline $\begin{array}{c}\text { Knowledge of improving the world's power } \\
\text { balance in terms of energy efficiency } \\
\text { improvements. }\end{array}$ & 1.02 & 1.13 & 1.46 & 1.18 & 1.63 & .21 \\
\hline \begin{tabular}{c} 
Knowledge index (composite scale) \\
\hline
\end{tabular}
\end{tabular}

\subsection{Evaluation measures}

Separate ANOVAs were conducted on the different evaluation items to see whether participants' evaluation of both the game and the Powerpoint presentation differed significantly. As can be seen from table 5, scores for how much participants judged the information presented to them credible differed significantly between the experimental condition $(\mathrm{M}=4.83 ; \mathrm{SD}=1.19)$ and the control condition $(\mathrm{M}=5.74 ; \mathrm{SD}=.75): \mathrm{F}(1,44)=9.64, \mathrm{p}<.01$. Participants in the control condition judged the credibility of the information presented in the Powerpoint significantly higher than participants in the experimental condition judged the information presented to them in the game. Looking at the ratings of participants of the statements "I learned a lot from [the game or the Powerpoint]", another significant difference was found: $\mathrm{F}(1,44)=4.81, \mathrm{p}=.03$. Participants in the control condition $(\mathrm{M}=$ 4.87; $\mathrm{SD}=1.77$ ) again rated this statement significantly higher than participants in the game condition $(\mathrm{M}=3.91 ; \mathrm{SD}=1.13)$ did.

Table 5. Means, standard deviations and significance levels of ratings of the evaluation items in both conditions

\begin{tabular}{|c|c|c|c|c|c|c|}
\hline & \multicolumn{2}{|c|}{ Exp. cond. } & \multicolumn{2}{|c|}{ Control cond. } & \multicolumn{2}{|c|}{ Significance } \\
\hline & M & SD & M & SD & $F(1,44)$ & $p$ \\
\hline $\begin{array}{l}\text { Overall, I found the game interesting to play / } \\
\text { Powerpoint interesting to read. }\end{array}$ & 5.91 & 1.08 & 5.30 & 1.40 & 2.73 & .11 \\
\hline $\begin{array}{l}\text { Overall, I enjoyed playing this game / the } \\
\text { Powerpoint presentation. }\end{array}$ & 5.70 & 1.06 & 5.22 & 1.45 & 1.64 & .21 \\
\hline $\begin{array}{l}\text { Credibility of the information presented in } \\
\text { the game / Powerpoint. }\end{array}$ & 4.83 & 1.19 & 5.74 & .75 & 9.64 & $.01 *$ \\
\hline $\begin{array}{l}\text { Personal relevance of the information } \\
\text { presented in the game / Powerpoint. }\end{array}$ & 4.30 & 1.52 & 4.65 & 1.61 & .57 & .46 \\
\hline Evaluation of "I learned a lot" & 3.91 & 1.13 & 4.87 & 1.77 & 4.81 & $.03 *$ \\
\hline
\end{tabular}

\section{Discussion}

The results of this study did not show a larger increase in attitude when playing a persuasive game than when reading information that is highly similar to the information presented in the game. The change in micro-level attitudes was not significantly different between the two conditions. The micro-level attitude index even suggests a trend towards a bigger increase of micro-level attitudes in the control condition, but neither this difference nor difference of separate items were significant. Also when macro-level attitudes are considered, no significant difference between conditions in change in attitude can be found, although attitudes increased more in the game condition in four out of eight separate macro-level attitude items, and the macro-level attitude index also hints towards a larger increase in experimental condition than in the control condition. But again, none of the differences between conditions were statistically significant. Since this was the case for both microand macro-level attitudes, it cannot be said - based on the results of this study - that there is really 
an effect of the persuasive game EnerCities in changing energy-related attitudes when a proper control condition is used.

When considering the differences in attitudes between pretest and posttest measurement, no clear persuasive effect could be found for participants who played the game or those who read the Powerpoint. A possible explanation for this lack of effects found might be that there was little room for improvement in attitude in the first place due to a very environmentally friendly sample. On average, participants already had relatively high energy-related attitudes before having been confronted with the persuasive content. Knol and De Vries [30] similarly noted that all participants had rather favorable energy-related attitudes.

The reason that energy-related attitudes were relatively favorable in this sample might also be because the answers were subject to a social desirability bias, in which respondents' answers are influenced by what they believe is the socially acceptable answer [17]. It could well be that participants' energy-related attitudes were generally influenced by ideas of a norm that they should have a favorable attitude towards sustainability topics at both moments of measurement. Vermeir and Verbeke [47] found that social norms were one of the reasons that consumers decided to buy sustainable products. Thus, perceptions of participants about what would be the right attitude to have, could have led to these rather favorable a priori energy-related attitudes, leaving the aforementioned limited room for improvement.

Analysis of the evaluation items included in the post-test questionnaire showed that participants did not significantly enjoy playing the game more than reading the Powerpoint, nor was there a significant difference in how interesting participants in the two conditions found the game to play or the Powerpoint to read. Game theorists argue that how 'fun' players find the game predicts their intrinsic motivation, engagement and immersion [29] [40]. It could be that, because participants did not find the game significantly more enjoyable than other participants found the Powerpoint presentation, a similar state of engagement and immersion was accomplished for participants in the control condition as for participants in the game condition. Moreover, if both the game and the Powerpoint received rather high evaluations of how 'fun' they were and the difference between the two conditions was not significant, there might have arguably also been no significant difference between the conditions in intrinsic motivation between the two conditions. Participants in both conditions could hence be intrinsically motivated [40] and therefore absorbed the information to a similar extent. Wouters et al.'s meta-analysis [49] actually found that serious games were not more motivating than conventional media. As such, the added value of the game in this aspect could have been nullified, which would explain the lack of difference in change of attitude between the two conditions. The purpose of this study was partially to test the effect of game features on an enlarged motivation experienced by players. The minimal differences in attitude change between the two conditions hint at the fact that this effect is apparently not that large.

In the literature research only one study was found that employed a research design in which a control condition was used that presented information similar to the information in the game: the study done by Lavender [31] [32]. Interestingly, this was also the only study that did not find a significant difference between these two conditions. It is remarkable that Lavender's study, using a research design rather similar to the design of this study also did not find significant differences. All other studies used in the literature review did not use a similar information control condition. This hints towards the idea that indeed the content of the game might be more important for persuasion than the game itself. Interestingly, this study did not find an increase in knowledge to be larger when playing the game than when reading the Powerpoint presentation. Even more so, for four of the five measures plus the composite measure, the increase in knowledge in the control condition was larger than in the experimental condition, but only in one case significantly.

An explanation for the absence of a larger change of knowledge found in the game condition could be that the information in the game was surrounded by too much extra information, such as graphic design and interactive elements added to make it more fun and engaging. This extra information could have distracted participants from the actual persuasive content [2]. As a result, a person has to process more information than he or she would have to when simply reading the persuasive information. Mayer [35] describes this as the idea that game features can increase extraneous processing: learners have to engage in extra cognitive processing that is not essential for the learning goals. If people do not have to engage in this extra processing, more cognitive resources remain available for the essential processing of the persuasive content. This argument would explain why the general tendency in this study was that participants in the control condition increased on average more in knowledge than participants in the game condition did: participants in the control 
group could focus on the actual content. They could thus solely engage in essential cognitive processing aimed at learning. Remarkably, participants who read the Powerpoint condition gave significantly higher ratings of that they had learned a lot than participants who played the game did. This self-reported knowledge measure corresponds with the trend of knowledge increasing slightly more in the control condition.

Interestingly, the original study of Knol and De Vries [30] found significant effects where the present study did not. It could be argued that the reason for this difference in results found is the difference in sample size. Indeed, statistical power to detect effects increases when sample sizes are larger [16] and clearly, the present study has a much smaller sample size than the original study (respectively $n=46$ and $n=653$ ). However, the sample size and reliability of measuring instruments of the present study still meet minimum requirements for statistical power (e.g.. a minimum of 20 participants per condition cf. [16]) so this option is unlikely. A second explanation for the difference in results is that in the original study playing the game was supplemented with a social environment that promoted favorable energy-related attitudes. Wouters et al. [49] explain that such contextual factors are important boosters of the effects of these kinds of games. They claim, based on their meta-review, that games combined with other instructional support like classroom discussion foster learning, probably due to a better integration process of the game with prior knowledge (see also [45]). The current study lacked such a context with supplemental influences, which might explain why the results are different from the results that the original study found. Yet, this result also indicates that the sheer effect of the game per se was not that strong in the present study. Important to take from this is hence that the interaction between context and the game is likely to constitute positive effects of persuasive games.

Arguably most important in explaining the difference in results between the two studies is, however, the fact that the present study used a 'similar info' control condition rather than a 'no info' control condition such as used in the original study to test whether this game was effective in persuading players. Using a control condition with similar information could be an explanation of why differences between conditions were not significant in the present study whereas they were in the original study.

\subsection{Limitations and implications for further research}

For various reasons, the results of this study should be considered preliminary and conclusions should be treated with caution. A first limitation of this study is that the sample is a well-educated, young and homogeneous sample. This could have affected the results of the assessment, as these students could have already been aware of ecological themes, making their progress in awareness and knowledge less evident. It would be interesting to do a replication study with a different sample consisting of more diverse people, e.g. a less educated group of participants or a group of older aged participants. A second limitation regarding the sample was the difference between the number of students involved in the primary study [30] and the present study. The sample size of the latter can be considered a limitation of the present study, seeing this could partially explain the difference between the two studies. Yet although the sample was not large, it was large enough to be able to detect significant differences. Our preference was to have high reliability and validity (e.g. we controlled what participants are doing during the study, assured equal conditions for all participants etc.) instead of a large sample size at the cost of reliability and validity as in Knol and De Vries [30].

Moreover, it is a limitation that the game was played once and only for twenty minutes. Increased exposure to the persuasive content can increase the knowledge acquisition process because it leads to redundant essential processing [35]. Wouters et al. [49] found that more can be learned from games when they are combined with other instructional support as well as used in multiple sessions so players can get used to the game. The study did not include investigations of whether attitude changes were sustained on the long term. The studies mentioned in the literature review could not provide unambiguous evidence of long-term effects either. It could be interesting for further research to investigate possible long-term effects as well.

Moreover, the literature review revealed that very few studies employ a research design that includes an informative control condition. Building upon the present study, it would be very interesting for future studies to also incorporate an improved design including an informative control condition as well, especially since the present study did not show that the game was more effective than the control condition.

The present study has tested overall effectiveness of the game in persuading players to adopt more sustainable attitudes. However, it was not tested what the result of specific game features was on 
persuasion. This concerns the "value-added" approach of game research [35]. Moreover, the literature review revealed few studies that evaluated the effectiveness of specific game features. A last suggestion for further research is to assess actual behavioral change after playing a persuasive game. The present study only investigated attitude and knowledge acquisition. It would be interesting for future studies to investigate how this extends to actual behavioral change. Although several psychological theorists posit that attitudes can lead to certain behavior [13], investigating the link between a persuasive game and behavior directly might be worthwhile. Research by Baranowski et al. [7] and Kato et al. [26] provides preliminary support for the claim that a persuasive game can lead to a change in behavior, but this link could be investigated further.

In short, based on the present study, the following recommendations for further research can be made:

1) Replicate this study using a sample consisting of more diverse participants

2) Replicate this study using a larger sample

3) Combine playing the game with other instructional methods and playing in multiple sessions

4) Investigate the long-term effects of playing a game in changing attitudes

5) Use informative control conditions for testing effectiveness of a game

6) Test what the result of specific game features is on persuasion through games

7) Assess actual behavioral change after playing a persuasive game

\section{Conclusion}

The goal of this study was to investigate whether there is really an effect of persuasive games. First, the question of whether evidence is available regarding the effectiveness of persuasive games was addressed. The review presented some studies in which evidence of persuasive effects of games was found. Evidence of successful change in attitude after playing a persuasive game can only be found in five of the sixty games reviewed, and also for five of the sixty games found research showed that they increased knowledge of players.

Second, this review study also placed important remarks at the research designs that were used by many scholars to evaluate effects of a game on attitude change. It became apparent that there is not only little empirical evidence currently available to show that games are indeed effective; studies often do not employ a research design that allows for cross-media comparison to investigate whether the effects can actually be attributed to the game or whether it is the information in the game that leads to these effects (see also [20]).

Third, from the empirical part of this study it can be concluded that playing a persuasive game does not increase attitudes more than conventional media can, at least based on the results of the current study. This study did find trends in the data implying that conventional media lacking game features might be even more effective both in changing attitudes as well as in transferring knowledge when similar persuasive content is presented. It is therefore hard to conclude at this moment that there really is an effect of persuasive games, based on the results of this study at least. Due to the critical remarks that this paper has made both regarding research designs as well as regarding the amount of research that has been done about games, this paper hopefully provides food for thought for game researchers. Hopefully, it will persuade scholars of the necessity of incorporating a proper control condition in their research.

\section{References}

References marked with an asterisk indicate studies included in the literature review. 
[1] *Alhabash, S., \& Wise, K., "Playing their game: Changing stereotypes of Palestinians and Israelis through videogame play." New Media \& Society, 1-19, 2014. DOI: $10.1177 / 1461444814525010$

[2] Annetta, L. A., Minogue, J., Holmes, S. Y., \& Cheng, M., "Investigating the impact of video games on high school students' engagement and learning about genetics". Computers \& Education, 53, 74-85, 2009. DOI: 10.1177/1461444814525010

[3] Aronson, E., Wilson, T. D., \& Akert, R. M., "Social Psychology”. Upper Saddle River, N.J.: Pearson Education, 2013.

[4] Bang, M., Torstensson, C., \& Katzeff, C., "The PowerHouse: A Persuasive Computer Game Designed to Raise Awareness of Domestic Energy Consumption”. In PERSUASIVE 2006 (123-132). Berlin-Heidelberg: Springer-Verlag, 2006. DOI: 10.1007/11755494_33

[5] *Barab, S. A., Sadler, T. D., Heiselt, C., Hickey, D., \& Zuiker, S., "Erratum to: Relating narrative, inquiry, and inscriptions: Supporting consequential play". Journal of Science Education and Technology, 19(4), 387-407, 2010. DOI: 10.1007/s10956-010-9220-0

[6] *Barab, S., \& Arici, A., "Mystery of Taiga River: Scientific Investigation Game". In Escudeiro P., \& Vaz de Carvalho C., (Eds.), Abstracts of Papers Presented at the 7th European Conference on Games Based Learning. Porto, Portugal, 2013.

[7] *Baranowski, T., Baranowski, J., Cullen, K. W., Marsh, T., Islam, N., Zakeri, I., De Moor, C., "Dietary Outcome Evaluation of a Multimedia Game". American Journal of Preventive Medicine, 24(1), 52-61, 2003. DOI:10.1016/S0749-3797(02)00570-6

[8] Bogost, I., "Persuasive games: the expressive power of videogames", Cambridge, MA: The MIT Press, 2007. DOI: 10.1093/llc/fqn029

[9] Brands, L., "Is collaboratief spelen van een game met een script beter dan individueel". Unpublished bachelor thesis, Universiteit Twente, 2014.

[10] *Burak, A., Keylor, E., \& Sweeney, T., "PeaceMaker: A video game to teach peace". In Intelligent Technologies for Interactive Entertainment (307-310). Springer Berlin Heidelberg, 2005. DOI: 10.1007/11590323_40

[11]Chen, S., \& Chaiken, S., "The heuristic-systematic model in its' broader context", In S. Chaiken, \& Y. Trope (Eds.), Dual Process Theories in Social Psychology. New York, NY: Guilford Press, 1999.

[12] Csikszentmihalyi, M., "Flow: the psychology of optimal experience", New York, NY: Harpers \& Row, 1990.

[13] De Vries, H., Mesters, I., van de Steeg, H., \& Honing, C., “The general public's information needs and perceptions regarding hereditary cancer: an application of the Integrated Change Model". Patient Education and Counseling, 56(2), 154-65, 2005. DOI: 10.1016/j.pec.2004.01.002

[14]*De Vries, P. W., \& Knol, E., "Serious Gaming as a Means to Change Adolescents' Attitudes Towards Saving Energy; Preliminary Results from the EnerCities Case". In EDEN Annual Conference (1-5), 2011.

[15] *Felicio, S. P. A. S., Silva, V. S. R., Dargains, A. R., Souza, P. R. A., Sampaio, F., Carvalho, P. V. R. Borges, M. R. S., "Stop Disasters Game Experiment with Elementary School Students in Rio de Janeiro: Building Safety Culture". In Proceedings of the 11th International ISCRAM Conference (585-591), 2014.

[16] Field, A., "Discovering Statistics Using SPSS", London, UK: SAGE, 2009. DOI: 10.1002/bjs. 7040

[17] Fisher, R. J., "Social Desirability Bias and the Validity of Indirect Questioning". Journal of Consumer Research, 20(2), 303-315, 1993. DOI: http://dx.doi.org/10.1086/209351

[18]Fogg, B. J., "Persuasive Technology: Using Computers to Change What We Think and Do", San Francisco, CA: Morgan Kauffman, 2003. DOI: 10.1145/764008.763957

[19] *Gerling, K., Mandryk, R., \& Birk, M., "The Effects of Embodied Persuasive Games on Player Attitudes Toward People Using Wheelchairs". In CHI'14: Proceedings of the 2014 CHI Conference on Human Factors in Computing Systems, 2014. DOI: $10.1145 / 2556288.2556962$

[20] Girard, C., Ecalle J., \& Magnant, A., "Serious games as new educational tools: how effective are they? A meta-analysis of recent studies". Journal of Computer Assisted Learning, 29, 207-219, 2013. DOI: 10.1111/j.1365-2729.2012.00489.x 
[21] *Gonzalez, C., Kampf, R., \& Martin, J. M., “Action diversity in a simulation of the IsraeliPalestinian conflict". Computers in Human Behavior, 28(1), 233-240, 2012. DOI: 10.1016/j.chb.2011.09.005

[22]*Gustafsson, A., Bång, M., \& Svahn, M., "Power explorer: a casual game style for encouraging long term behavior change among teenagers". In Proceedings of the International Conference on Advances in Computer Entertainment Technology (pp. 182189), 2009. DOI: 10.1145/1690388.1690419

[23]* Gustafsson, A., Katzeff, C., \& Bang, M., "Evaluation of a pervasive game for domestic energy engagement among teenagers". Computers in Entertainment, 7(4-54), 1-9, 2009. DOI: $10.1145 / 1658866.1658873$

[24] Honey, M. A., \& Hilton, M. (Eds.). "Learning science through computer games and simulations", Washington, DC: The National Academies Press, 2011.

[25]*Isaacs, J. A., Dolinsky, B., Qualters, D. M., \& Laird, J. T., "Engineering Decisions to Green the Automobile Supply Chain”. In Cozzi A. \& Ohji T., (Eds.), Environmental Issues and Waste Management Technologies in the Materials and Nuclear Industries XII (225234). Hoboken, NJ: John Wiley \& Sons, 2009. DOI: 10.1002/9780470538371.ch21

[26] *Kato, P. M., Cole, S. W., Bradlyn, a S., \& Pollock, B. H., “A video game improves behavioral outcomes in adolescents and young adults with cancer: a randomized trial". Pediatrics, 122(2), 305-317, 2008. DOI: 10.1542/peds.2007-3134

[27] Katsaliaki, K., \& Mustafee, N., “A Survey of Serious Games on Sustainable Development”. In Proceedings of the 2012 Winter Simulation Conference (Vol. 7), 2012. DOI: 10.1109/WSC.2012.6465182

[28] Kiser, C., "Ondersteuning in Game-gebaseerd Leren: De Invloed van Testen en Feedback op Leren met Games". Unpublished bachelor thesis, Universiteit van Twente, 2013.

[29] Klimmt, C., "Serious Games and Social Change: Why They (Should) Work". In Ritterfeld U., Cody M., \& Vorderer P., (Eds.), Serious Games: Mechanisms and Effects (248-270). New York, NY: Routledge, 2009.

[30]*Knol, E., \& Vries, P. De., "EnerCities, a Serious Game to Stimulate Sustainability and Energy Conservation: Preliminary Results”. eLearning Paper, 25, 1-10, 2011.

[31] *Lavender, T., "Games Just Wanna Have Fun ... Or Do They? Measuring the Effectiveness of Persuasive Games". In Proceedings of the CGSA 2006 Symposium (1-7), 2006.

[32] *Lavender, T. J., "Homeless: It's No Game - Measuring the Effectiveness of a Persuasive Videogame". Unpublished master thesis, Simon Fraser University, 2008.

[33] Liarakou, G., Sakke, E., Gavrilakis, C., \& Tsolakidis, C., "Evaluation of Serious Games, as a Tool for Education for Sustainable Development". In Proceedings of the EDEN Annual Conference, 2011.

[34]Mayer, R. E., “Multimedia Learning”. New York, NY: Cambridge University Press, 2001.

[35] Mayer, R. E., "Multimedia learning and games". In Tobias S., \& Fletcher J., D., (Eds.), Computer games and instruction (281-305), Greenwich, CT: Information Age Publishing., 2011

[36] Michalos, A. C., Creech, H., McDonald, C., \& Kahlke, P. M. H., "Measuring Knowledge, Attitudes and Behaviours towards Sustainable Development: Two Exploratory Studies".IISD, 1, 2009. DOI: 10.1007/s11205-010-9620-9

[37] *Michelin, M., "Can a game put engineering students in an active learning mode ? A first experiment in sustainable agriculture teaching". In Elleithy K., (Ed.), Advances in Computer, Information, and Systems Sciences, and Engineering (p343-349). Springer, 2006. DOI: $10.1007 / 1-4020-5261-8 \_53$

[38] Murray, J., "Hamlet on the Holodeck: The Future of Narrative in Cyberspace". Cambridge, MA: MIT Press, 1997. DOI: 10.1177/135485659800400413

[39] *Peng, W., "Design and evaluation of a computer game to promote a healthy diet for young adults". Health Communication, 24(2), 115-27, 2009. DOI:10.1080/10410230802676490

[40] Prensky, M., "The Motivation of Gameplay". On the Horizon, 10(1), 1-14, 2002. DOI: http://dx.doi.org/10.1108/10748120210431349

[41] Ritterfeld, U., Cody, M., \& Vorderer, P., "Introduction". In Ritterfeld U., Cody M., \& Vorderer P., (Eds.), Serious Games: Mechanisms and Effects (3-9). London: Routledge, 2009.

[42] Ruggiero, D., "The Effect of a Persuasive Game on Attitude towards the Homeless". Unpublished thesis, Purdue University, 2013. 
[43] Shettleworth, S. J., “Cognition, Evolution and Behavior”. New York, NY: Oxford, 2010.

[44] Spek, E. van der, "Experiments in serious game design: a cognitive approach". Unpublished $\mathrm{PhD}$ thesis, Utrecht University, the Netherlands, 2011.

[45] *Tragazikis, P., \& Meimaris, M., "Engaging kids with the concept of sustainability using a commercial video game - a case study". In Pan Z., Cheok A.D., Muller W., \& Change M., (Eds.), Transactions on Edutainment III (1-12), 2009. DOI: 10.1007/978-3-642-11245-4_1

[46] U.S. Energy Information Administration, “Annual Energy Outlook 2014”. Retrieved from http://www.eia.gov/forecasts/aeo/pdf/0383(2014).pdf, 2014.

[47] Vermeir, I. \& Verbeke, W., "Sustainable Food Consumption: Exploring the Consumer "Attitude - Behavioral Intention" Gap". Journal of Agricultural and Environmental Ethics, 19, 169-194, 2006. DOI: 10.1007/s10806-005-5485-3

[48] *Williams, O., Hecht, M. F., DeSorbo, A. L., Huq, S., \& Noble, J. M., "Effect of a novel video game on stroke knowledge of 9- to 10-year-old, low-income children". Stroke; a Journal of Cerebral Circulation, 45(3), 889-92, 2014. DOI: 10.1161/STROKEAHA.113.002906

[49] Wouters, P., van Nimwegen, C., van Oostendorp, H., \& van der Spek, E. D., "A MetaAnalysis of the Cognitive and Motivational Effects of Serious Games". Journal of Educational Psychology, 105(2), 249-265, 2013. 
Appendix: Summary of games with studies investigating their effectiveness

\begin{tabular}{|c|c|c|c|c|c|c|c|c|}
\hline \multicolumn{3}{|c|}{ Description } & \multicolumn{2}{|c|}{ Research design } & \multicolumn{3}{|c|}{ Outcome measures } & \multirow[t]{2}{*}{ Effects found } \\
\hline Study & Name & Topic & $\begin{array}{l}\text { Control } \\
\text { condition }\end{array}$ & $\begin{array}{l}\text { Repeated } \\
\text { measurements }\end{array}$ & $\begin{array}{l}\text { Attitude } \\
\text { change } \\
\text { evaluated }\end{array}$ & $\begin{array}{l}\text { Knowledge } \\
\text { change } \\
\text { evaluated }\end{array}$ & $\begin{array}{l}\text { Behavioral } \\
\text { change } \\
\text { evaluated }\end{array}$ & \\
\hline $\begin{array}{l}\text { Gerling, Mandryk, Birk, Miller, } \\
\& \text { Orji (2014) }\end{array}$ & $\begin{array}{l}\text { Birthday } \\
\text { Party }\end{array}$ & $\begin{array}{l}\text { People Using } \\
\text { Wheelchairs }\end{array}$ & $\begin{array}{l}\text { no (only } \\
\text { wheelchair } \\
\text { vs. } \\
\text { joystick) }\end{array}$ & $\begin{array}{l}\text { pre, post, } \\
\text { follow-up }\end{array}$ & yes & no & no & $\begin{array}{l}\text { Attitude: attitude increased significantly for some of the measures from } \\
\text { pretest to immediately after. Changes in discrimination were significant } \\
\text { for wheelchair condition but not for joystick condition. Effect was also } \\
\text { significant at follow-up measurement for wheelchair condition, not for } \\
\text { joystick condition. Changes in prospects were significant for joystick } \\
\text { condition but not for wheelchair condition. Overall, the game was } \\
\text { successful in changing attitudes; some changes were sustained at } \\
\text { follow-up (only regarding discrimination in embodied / wheelchair } \\
\text { condition). }\end{array}$ \\
\hline $\begin{array}{l}\text { Williams, Hecht, DeSorbo, Huq, } \\
\text { \& Noble (2014) }\end{array}$ & $\begin{array}{l}\text { Clot } \\
\text { Buster }\end{array}$ & $\begin{array}{l}\text { Health } \\
\text { education / } \\
\text { stroke } \\
\text { knowledge }\end{array}$ & no & $\begin{array}{l}\text { pre, post, } \\
\text { follow-up }\end{array}$ & no & yes & no & $\begin{array}{l}\text { Knowledge: significant improvement of stroke symptom total scores, } \\
\text { calling } 911 \text { and individual stroke knowledge post-test vs. pre-test. No } \\
\text { significantly different composite stroke knowledge scores for } \\
\text { participants that continued playing game at home = no long-term } \\
\text { effects found. }\end{array}$ \\
\hline $\begin{array}{l}\text { Knol \& De Vries (2011) and De } \\
\text { Vries \& Knol (2011) }\end{array}$ & EnerCities & $\begin{array}{l}\text { Sustainable } \\
\text { urban } \\
\text { development }\end{array}$ & yes, no info & only post & yes & indirectly & no & $\begin{array}{l}\text { Attitude: significant difference between game and control condition. } \\
\text { Knowledge: no real knowledge measures but significant difference in } \\
\text { awareness of game condition vs. control condition. }\end{array}$ \\
\hline Lavender $(2008 ; 2006)$ & $\begin{array}{l}\text { Homeless: } \\
\text { it's no } \\
\text { game }\end{array}$ & Homelessness & $\begin{array}{l}\text { yes, no info } \\
+ \text { narrative } \\
\text { only }\end{array}$ & $\begin{array}{l}\text { pre, post, } \\
\text { follow-up }\end{array}$ & yes & yes & no & $\begin{array}{l}\text { Attitude: no significant change in either interest or attitude in either of } \\
\text { the } 3 \text { groups. Significant difference between game condition and other } \\
2 \text { groups in how sympathetic people became to homeless. } \\
\text { Knowledge: no significant change in knowledge (pre-test vs. post-test) } \\
\text { in either of the three groups. }\end{array}$ \\
\hline $\begin{array}{l}\text { Barab \& Arici (2013) and Barab, } \\
\text { Sadler, Heiselt, Hickey, \& } \\
\text { Zuiker (2010) }\end{array}$ & $\begin{array}{l}\text { Mystery of } \\
\text { Taiga } \\
\text { River }\end{array}$ & $\begin{array}{l}\text { Environment / } \\
\text { healthy river } \\
\text { system }\end{array}$ & yes, no info & pre \& post & no & yes & no & $\begin{array}{l}\text { Knowledge: both conditions significant learning gains ( }=\text { increase } \\
\text { knowledge post-test vs. pre-test). Learning gains significantly greater } \\
\text { in experimental condition than control condition = interaction effect of } \\
\text { condition and measurement time. }\end{array}$ \\
\hline $\begin{array}{l}\text { Burak, Keylor, \& Sweeney } \\
\text { (2005), Alhabash \& Wise (2012, } \\
\text { 2014) and Gonzalez \& Czlonka } \\
\text { (2012) }\end{array}$ & $\begin{array}{l}\text { Peace } \\
\text { Maker }\end{array}$ & $\begin{array}{l}\text { Israeli- } \\
\text { Palestinian } \\
\text { conflict }\end{array}$ & no & pre $\&$ post & yes & no & no & $\begin{array}{l}\text { Attitude: significant attitude change towards Palestinians (pre-test } \\
\text { difference became non-significant at post-test). Implicit attitude } \\
\text { measures did not change significantly. }\end{array}$ \\
\hline
\end{tabular}




\begin{tabular}{|c|c|c|c|c|c|c|c|c|}
\hline \multicolumn{3}{|c|}{ Description } & \multicolumn{2}{|c|}{ Research design } & \multicolumn{3}{|c|}{ Outcome measures } & \multirow[t]{2}{*}{ Effects found } \\
\hline Study & Name & Topic & $\begin{array}{l}\text { Control } \\
\text { condition }\end{array}$ & $\begin{array}{l}\text { Repeated } \\
\text { measurements }\end{array}$ & $\begin{array}{l}\text { Attitude } \\
\text { change } \\
\text { evaluated }\end{array}$ & $\begin{array}{l}\text { Knowledge } \\
\text { change } \\
\text { evaluated }\end{array}$ & $\begin{array}{l}\text { Behavioral } \\
\text { change } \\
\text { evaluated }\end{array}$ & \\
\hline $\begin{array}{l}\text { Gustafsson, Katzeff, \& Bang } \\
\text { (2009) }\end{array}$ & $\begin{array}{l}\text { Power } \\
\text { Agent }\end{array}$ & $\begin{array}{l}\text { Reducing } \\
\text { energy } \\
\text { consumption }\end{array}$ & no & $\begin{array}{l}\text { pre, during, } \\
\text { post }\end{array}$ & no & no & yes & $\begin{array}{l}\text { Behavior: significantly lower consumption during game play, but more } \\
\text { consumption right before and after. Change was not lasting after play } \\
\text { ended. }\end{array}$ \\
\hline $\begin{array}{l}\text { Gustafsson, Bang, \& Svahn } \\
\text { (2009) }\end{array}$ & $\begin{array}{l}\text { Power } \\
\text { explorer }\end{array}$ & $\begin{array}{l}\text { Energy } \\
\text { management }\end{array}$ & yes, no info & $\begin{array}{l}\text { pre, during, } \\
\text { post }\end{array}$ & yes & yes & yes & $\begin{array}{l}\text { Attitude: players in game group increased attitude and players in } \\
\text { control condition decreased attitude (statistically significant } \\
\text { difference). } \\
\text { Knowledge: no significant increases on knowledge test for either of the } \\
\text { two conditions. } \\
\text { Behavior: during game, experimental condition consumed significantly } \\
\text { less than control condition. Also significant difference after game trial. }\end{array}$ \\
\hline $\begin{array}{l}\text { Kato, Cole, Bradlyn, \& Pollock } \\
\text { (2008) }\end{array}$ & Re-Mission & $\begin{array}{l}\text { Health } \\
\text { education }\end{array}$ & yes, no info & pre $\&$ post & indirectly & yes & yes & $\begin{array}{l}\text { Behavior: significant improvement of treatment adherence after playing } \\
\text { game. } \\
\text { Attitude: significant increase of cancer-related self-efficacy (= } \\
\text { indirectly attitude), significantly greater increase in game group vs. } \\
\text { control group. } \\
\text { Knowledge: both increase, but significantly greater increase in cancer- } \\
\text { related knowledge over time in intervention group vs. control group. }\end{array}$ \\
\hline Peng (2009) & $\begin{array}{l}\text { RightWay } \\
\text { Cafe }\end{array}$ & $\begin{array}{l}\text { Healthy } \\
\text { nutrition }\end{array}$ & yes, no info & $\begin{array}{l}\text { pre, post, } \\
\text { follow-up }\end{array}$ & indirectly & yes & no & $\begin{array}{l}\text { Attitude and knowledge: knowledge, self-efficacy and perceived } \\
\text { benefits significantly greater at post-test (controlling for pre-test) in } \\
\text { game group vs. Control group. Perceived barriers significantly lower in } \\
\text { game group. Intention to eat healthier significantly greater in treatment } \\
\text { group. Effect not sustained on long-term. }\end{array}$ \\
\hline $\begin{array}{l}\text { Isaacs, Dolinsky, Qualters, \& } \\
\text { Laird (2009) }\end{array}$ & Shortfall & $\begin{array}{l}\text { Green } \\
\text { automobile } \\
\text { supply chain }\end{array}$ & no & $\begin{array}{l}\text { pre, post, } \\
\text { follow-up }\end{array}$ & no & yes & no & $\begin{array}{l}\text { Knowledge: self-reported measures indicate more knowledge and } \\
\text { confidence about the topic at post-test measurement vs. pre-test } \\
\text { measurement. }\end{array}$ \\
\hline Michelin (2006) & $\begin{array}{l}\text { Shrub } \\
\text { Battle }\end{array}$ & $\begin{array}{l}\text { Ecosystem } \\
\text { management }\end{array}$ & no & pre $\&$ post & no & yes & no & $\begin{array}{l}\text { Knowledge: better understanding of farming after playing the game, } \\
\text { but no statistics provided in article. }\end{array}$ \\
\hline Baranowski et al. (2003) & $\begin{array}{l}\text { Squire's } \\
\text { Quest }\end{array}$ & $\begin{array}{l}\text { Healthy } \\
\text { nutrition }\end{array}$ & yes, no info & pre \& post & no & no & yes & $\begin{array}{l}\text { Behavior: participants increased consumption of fruit, juice and } \\
\text { vegetbles significantly more after playing the game than participants in } \\
\text { the control condition did, after controlling for baseline consumption. }\end{array}$ \\
\hline Felicio et al. (2014) & $\begin{array}{l}\text { Stop } \\
\text { Disasters! }\end{array}$ & $\begin{array}{l}\text { Global climate } \\
\text { change } \\
\text { management }\end{array}$ & no & pre \& post & no & yes & no & $\begin{array}{l}\text { Knowledge: playing game raised awareness of the topic. Also some } \\
\text { gain in knowledge. }\end{array}$ \\
\hline
\end{tabular}




\begin{tabular}{|c|c|c|c|c|c|c|c|c|}
\hline \multicolumn{3}{|c|}{ Description } & \multicolumn{2}{|c|}{ Research design } & \multicolumn{3}{|c|}{ Outcome measures } & Effects found \\
\hline Study & Name & Topic & $\begin{array}{l}\text { Control } \\
\text { condition }\end{array}$ & $\begin{array}{l}\text { Repeated } \\
\text { measurements }\end{array}$ & $\begin{array}{l}\text { Attitude } \\
\text { change } \\
\text { evaluated }\end{array}$ & $\begin{array}{l}\begin{array}{l}\text { Knowledge } \\
\text { change } \\
\text { evaluated }\end{array} \\
\end{array}$ & $\begin{array}{l}\text { Behavioral } \\
\text { change } \\
\text { evaluated }\end{array}$ & Results \\
\hline Tragazikis \& Meimaris (2009) & $\begin{array}{l}\text { THE SIMS } \\
\text { adapted }\end{array}$ & $\begin{array}{l}\text { Environmental } \\
\text { consumer } \\
\text { choices }\end{array}$ & no & $\begin{array}{l}\text { post } \& \text { follow- } \\
\text { up }\end{array}$ & yes & No & no & $\begin{array}{l}\text { Attitude: qualitative research indicates attitude changes, but not backed } \\
\text { up by statistics. }\end{array}$ \\
\hline
\end{tabular}

